\title{
파워반도체용 $\mathrm{Cu} / \mathrm{Sn} / \mathrm{Ag}$ 와 $\mathrm{Ni} / \mathrm{Sn} / \mathrm{Ag}$ 천이액상접합 최적 공정 조건과 전단강도
}

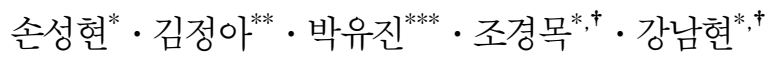 \\ *부산대학교 재료공학부 \\ **삼성전기 기판솔루션사업부 \\ ***캘리포니아 대학교 샌디에이고 재료공학부
}

\section{Optimum Process Condition and Shear Strength of Transient Liquid Phase Bonded $\mathrm{Cu} / \mathrm{Sn} / \mathrm{Ag}$ and Ni/Sn/Ag Structures for Power Semiconductor Interconnect}

\author{
Sunghyun Sohn*, Jeonga Kim**, Yujin Park***, Kyung Mox Cho*, and Namhyun Kang*, ${ }^{*}$ \\ *Department of Materials Science \& Engineering, Pusan National University, Busan, 46241, Korea \\ **Substrate Solution, Samsung Electro-Mechanics, Busan, 46754, Korea \\ ***Department of Materials Science \& Engineering, University of California at San Diego, CA 92093, USA \\ †Corresponding author : chokm@pusan.ac.kr, nhkang@pusan.ac.kr
}

(Received June 6, 2019 ; Revised July 5, 2019 ; Accepted July 11, 2019)

\begin{abstract}
Transient Liquid Phase Bonding (TLPB) is one of the promising processes for interconnecting power semiconductors, which are usually used at high temperature. However, the TLPB process parameters needed to ensure robust interconnection have not been systematically studied. In this study, TLPB was conducted with various bonding temperatures and times. Sandwich structures made of $\mathrm{Cu} / \mathrm{Sn} / \mathrm{Cu}, \mathrm{Ag} / \mathrm{Sn} / \mathrm{Ag}$, and $\mathrm{Ni} / \mathrm{Sn} / \mathrm{Ni}$ were processed at 250 and $280{ }^{\circ} \mathrm{C}$ for 1,2 , and $3 \mathrm{~h}$, respectively. The microstructure of the interconnections was analyzed with scanning emission microscopy equipped with energy dispersive spectroscopy. Then dissimilar metalized $\mathrm{Cu} / \mathrm{Sn} / \mathrm{Ag}$ and $\mathrm{Ni} / \mathrm{Sn} / \mathrm{Ag}$ sandwich structures processed at $280{ }^{\circ} \mathrm{C}$ for 1,2 , and $3 \mathrm{~h}$. The fracture surface of $\mathrm{Cu} / \mathrm{Sn} / \mathrm{Ag}$ consisted of $\mathrm{Ag}_{3} \mathrm{Sn}$ with shear bands, and the shear strength was $30 \mathrm{MPa}$ on average. The fracture surface of $\mathrm{Ni} / \mathrm{Sn} / \mathrm{Ag}$ consisted of $\mathrm{Ni}_{3} \mathrm{Sn}_{4}$ and $\mathrm{Ag}_{3} \mathrm{Sn}$ with shear bands, and the shear strength was $31 \mathrm{MPa}$ on average. The minimum bonding time for reliable interconnection was 1 and $2 \mathrm{~h}$ for $\mathrm{Cu} /$ $\mathrm{Sn} / \mathrm{Ag}$ and $\mathrm{Ni} / \mathrm{Sn} / \mathrm{Ag}$, respectively.
\end{abstract}

Key Words : Transient liquid phase bonding, Metailization, Interconnect, Power semiconductor, Intermetallic compounds, Lap-shear test

\section{1. 서 론}

최근 넓은 에너지 밴드 갭을 가지는 $\mathrm{SiC}$ 혹은 $\mathrm{GaN}$ 에 대한 수요가 증가하고 있다. 이러한 $\mathrm{SiC}, \mathrm{GaN}$ 반 도체 부품들은 높은 열전도도와 고온에서의 안정성 등 이 큰 특징이며 특히 고온에서의 안정성으로 인해 높은 작동 온도를 요구하는 전자부품에 주로 사용된다 ${ }^{1)}$. 따
라서 고온에서의 안정성 요구는 칩과 기판을 연결하는 접합부의 문제로 귀결된다. 상용화되고 있는 무연 고온 솔더 접합부의 재융점 온도는 $250{ }^{\circ} \mathrm{C}$ 미만이므로 ${ }^{2,3)}$ 사용 환경에 따라 최대 $600{ }^{\circ} \mathrm{C}$ 의 재융점 온도를 요구 하는 파워반도체의 접합재료로 적합하지 않다 ${ }^{4)}$.

천이액상접합(Transient Liquid Phase Bonding, TLPB)은 기존의 무연 솔더를 이용해 높은 재융점 온 도를 갖는 금속간 화합물로 구성된 접합부를 얻는 공정

Journal of Welding and Joining, Vol.37 No.4(2019) pp363-368

https://doi.org/10.5781/JWJ.2019.37.4.11 
이다 ${ }^{2)} \mathrm{TLPB}$ 의 재융점 온도는 칩 혹은 기판에 증착된 metalization의 종류와 솔더로 사용되는 interlayer의 종류에 의해 결정되는 금속간 화합물의 융점에 의존한 다. 예를 들면, $\mathrm{Ni}_{3} \mathrm{Sn}_{4}, \mathrm{Ag}_{3} \mathrm{Sn}, \mathrm{Cu}_{6} \mathrm{Sn}_{5}, \mathrm{Cu}_{3} \mathrm{Sn}$ 의 융 점은 각각 $800,480,415,676{ }^{\circ} \mathrm{C}$ 이다. $\mathrm{Cu}, \mathrm{Ni}, \mathrm{Ag}$ 등의 metalization과 대표적 무연 솔더인 $\mathrm{Sn}$ 으로 구 성된 금속간 화합물 접합부는 기존의 무연 솔더로 이루 어진 접합부의 융점보다 높으므로 파워반도체 환경에 적합하다.

$\mathrm{TLPB}$ 의 중요성은 대두되고 있으나 압력, 온도와 시 간에 따른 TLPB 특성과 이종 metalization에 따른 접합부의 분석 및 특성평가는 활발하게 이루어지고 있 지 않다. 따라서 본 연구는 $\mathrm{Sn}$ 을 interlayer, $\mathrm{Cu}, \mathrm{Ni}$, $\mathrm{Ag}$ 를 metalization으로 하여 온도와 접합 시간에 따 른 동종 접합부의 특성과 이종 metalization TLPB 접 합부의 특성평가를 수행하였다. 이를 통해 최적의 TLPB 공정 조건과 접합부의 적용 가능성에 대해 논하였다.

\section{2. 실험 방법}

본 연구는 metalization /Sn interlayer/ metalization 샌드위치 구조를 TLPB 실험에 이용하였고, Fig. 1은 접합부의 구조 모식도를 나타내었다. Metalization 으로는 $5 \mathrm{~mm}(\mathrm{~L}) \times 5 \mathrm{~mm}(\mathrm{~W}) \times 1 \mathrm{~mm}(\mathrm{~T})$ 크기 의 $\mathrm{Cu}^{-}$(순도 $99.99 \%$ ), $\mathrm{Ni}-$ (순도 $99 \%$ ), $\mathrm{Ag}$-(순도 99.95\%) 시트를 사용하였다. Sn interlayer (순도 $99.8 \%)$ 는 $5 \mathrm{~mm}(\mathrm{~L}) \times 5 \mathrm{~mm}(\mathrm{~W}) \times 50 \mu \mathrm{m}(\mathrm{T})$ 크 기의 thin foil을 사용하였다. 접합 시 접합계면이 충분히 접촉할 수 있게 $100 \mathrm{~g}$ 분동을 사용하여 약 $0.04 \mathrm{MPa}$ 의 압력을 가하였다. Metalization으로 사용된 재료들은 1200 grit 까지 $\mathrm{SiC}$ paper로 연마 후 $3 \mu \mathrm{m}$ 다이아몬드 서스펜션을 이용하여 표면을 연마하였다. Sn interlayer 는 표면 활성화를 위해 염산 $9 \mathrm{vol} \%$ 와 질산 $4 \mathrm{vol} \%$ 를 혼합한 에탄올 수용액에 산세처리를 진행하였다. 준 비된 metalization 시트와 interlayer를 Fig. 1 과 같 이 적층 후 진공분위기 $\left(10^{-1}\right.$-torr)에서 접합 온도 250 , $280{ }^{\circ} \mathrm{C}$ 그리고 각각 $1,2,3$ 시간 동안 접합하였다.

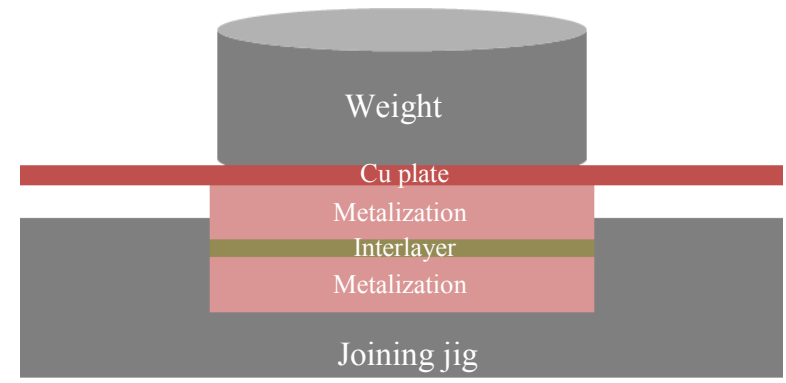

Fig. 1 Schematic diagram of sandwich structure for TLPB
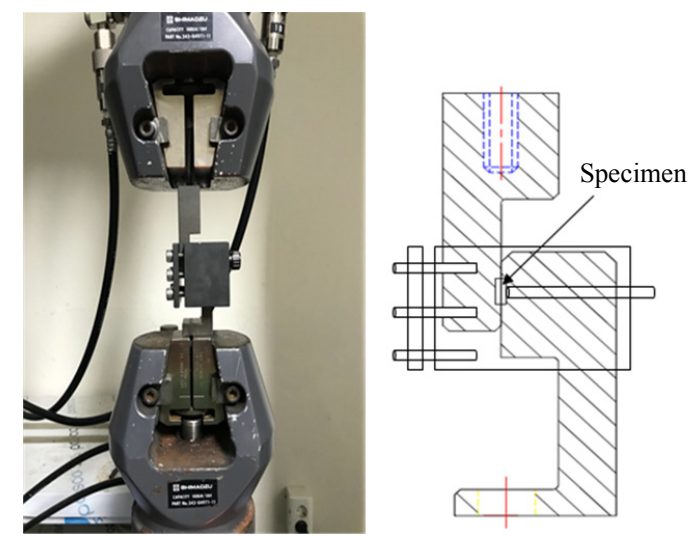

Fig. 2 Lap-shear test of TLPB specimens (left) and schematic diagram (right)

접합면 관찰을 위해 $\mathrm{TLPB}$ 시편은 구리 레진에 마운 팅 후 $1 \mu \mathrm{m}$ 까지 연마하여 주사전자현미경(Scanning Electron Microscopy, SEM)으로 관찰하였다. 접합부의 기공률 분석은 Image analysis (Image Pro-Plus)를 이용하였다. 접합면의 기계적 성질은 Fig. 2와 같이 lapshear test로 측정하였고, strain rate는 $0.3 \mathrm{~mm} / \mathrm{min}$ 로 수행하였다. Lap shear test시 TLPB의 두께가 다 른 점을 감안하여 볼트 체결을 통해 지그 내 시편의 위 치를 조절하여 lap shear test 부분의 두께를 일정하 게 하였다. 시편을 지그 안에 고정시키기 위해 최소한 의 볼트 체결을 하여 시편을 고정하였다 (Fig. 2). Lapshear test 후 전단파면은 SEM으로 관찰하였다.

\section{3. 실험결과 및 고찰}

\section{1 동종 metalization TLPB}

Fig. 3은 $\mathrm{Cu} / \mathrm{Sn} / \mathrm{Cu}$ 의 접합 온도와 시간에 따른 접 합부 미세조직을 나타낸다. $250{ }^{\circ} \mathrm{C} 1$ 시간 조건에서 생 성된 상은 $\mathrm{Cu}-\mathrm{Sn}$ 상태도에서와 같이 $\mathrm{Cu}_{6} \mathrm{Sn}_{5}$ 와 $\mathrm{Cu}_{3} \mathrm{Sn}$ 이 형성되었다(Fig. $3 \mathrm{a}$ ). TLPB 시 $\mathrm{Cu}$ 와 $\mathrm{Sn}$ 의 계면에

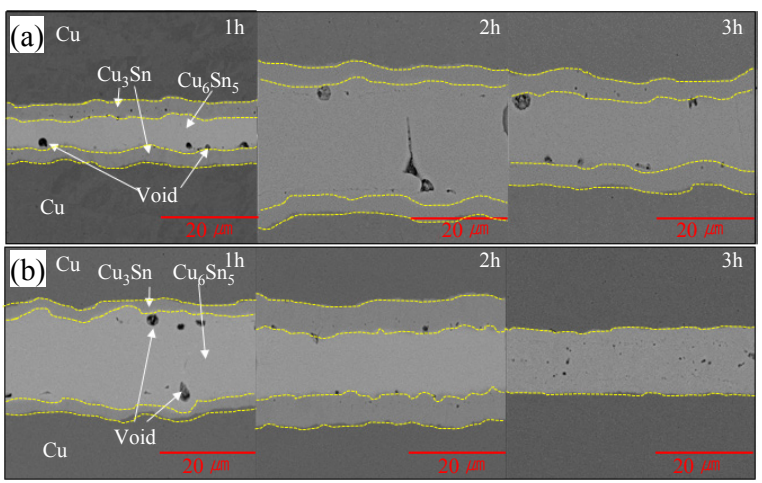

Fig. 3 Cross section images of $\mathrm{Cu} / \mathrm{Sn} / \mathrm{Cu} \mathrm{TLPB}$ at various temperatures: (a) $250{ }^{\circ} \mathrm{C}$ and (b) $280{ }^{\circ} \mathrm{C}$ 
서 우선적으로 $\mathrm{Cu}_{6} \mathrm{Sn}_{5}$ 이 형성된다. 이 후 $\mathrm{Cu}$ 의 $\mathrm{dis}^{-}$ solution이 증가함에 따라 $\mathrm{Cu}$ 와 $\mathrm{Cu}_{6} \mathrm{Sn}_{5}$ 의 계면에서 $\mathrm{Cu}_{3} \mathrm{Sn}$ 이 형성된다. 접합 온도를 $280{ }^{\circ} \mathrm{C}$ 로 증가한 경 우에도 $\mathrm{Cu}-\mathrm{Sn}$ 금속간 화합물이 형성된다(Fig. $3 \mathrm{~b}$ ). 하지만 접합 시간이 증가함에 따라 접합부의 기공이 현 저하게 감소하였으며, 3 시간에서는 접합부가 완전히 $\mathrm{Cu}_{3} \mathrm{Sn}$ 단상으로 이루어졌다. 이는 온도가 증가함에 따 라 $\mathrm{Sn}$ 내에서 $\mathrm{Cu}$ 의 확산계수가 증가하므로 금속간 화 합물의 생성 속도가 증가하였기 때문이다. 접합층의 두 께는 Fig. 3b가 Fig. 3a보다 평균적으로 $5 \mu \mathrm{m}$ 두꺼웠 다. 두꺼운 접합부는 작동환경에서 칩과 기판의 열팽창 계수 차이에 의해 발생하는 응력 구배를 감소시킨다 ${ }^{5)}$. 따라서 $\mathrm{Cu} / \mathrm{Sn} / \mathrm{Cu} \mathrm{TLPB}$ 최적 온도 조건은 균일한 금 속간 화합물 형성, 기공률 감소, 접합 두께가 증가하는 $280{ }^{\circ} \mathrm{C}$ 임을 확인하였다.

Fig. 4는 $\mathrm{Ag} / \mathrm{Sn} / \mathrm{Ag}$ 의 접합 온도와 시간에 따른 접 합부 미세조직을 나타낸다. $\mathrm{Ag}-\mathrm{Sn}$ 상태도를 따라 metalization으로 사용된 $\mathrm{Ag}$ 가 액상의 $\mathrm{Sn}$ 에 dissolution 이 되면서 $\mathrm{Ag}$ 와 $\mathrm{Sn}$ 의 계면에서 $\mathrm{Ag}_{3} \mathrm{Sn}$ 이 생성 되었다. 지난 연구에서 $\mathrm{Ag}_{3} \mathrm{Sn}$ 의 형상은 주로 scallop type으로 형성되어, $\mathrm{Ag}_{3} \mathrm{Sn}$ 만나는 접합부 중간 계면에서 voids 가 존재할 수 있다고 하였다 ${ }^{6)}$. 이러한 경향은 Fig. 4 에서도 확인할 수 있으며, 특히 접합 조건이 $250{ }^{\circ} \mathrm{C} 1$ 시간일 경우 두드러지게 나타났다. 기공 분율은 $250{ }^{\circ} \mathrm{C}$ 접합온도에서 접합시간이 1-3시간으로 증가하면서 $8 \%$, $2 \%, 0.7 \%$ 로 감소하였고, $280{ }^{\circ} \mathrm{C}$ 접합온도에서 기공 분율은 접합 시간이 증가함에 따라 $7 \%, 0.3 \%, 0.3 \%$ 로 감소하였다. 접합부의 두께는 평균적으로 $280{ }^{\circ} \mathrm{C}$ 접 합온도의 경우 $10 \mu \mathrm{m}$ 작았다. 따라서 $\mathrm{Ag} / \mathrm{Sn} / \mathrm{Ag} \mathrm{TLPB}$ 최적 온도 조건은 균일한 금속간 화합물 형성과 기공률 이 감소하는 $280{ }^{\circ} \mathrm{C}$ 이다.

Fig. 5 는 $\mathrm{Ni} / \mathrm{Sn} / \mathrm{Ni}$ TLPB 접합부 미세조직을 나타 낸다. $\mathrm{Ni} / \mathrm{Sn} / \mathrm{Ni}$ 에서 형성되는 금속간 화합물은 $\mathrm{Ni}^{-}$ $\mathrm{Sn}$ 상태도에 따라 $\mathrm{Ni}_{3} \mathrm{Sn}_{4}$ 가 형성된다. $\mathrm{Ni}_{3} \mathrm{Sn}_{4}$ 의 금속
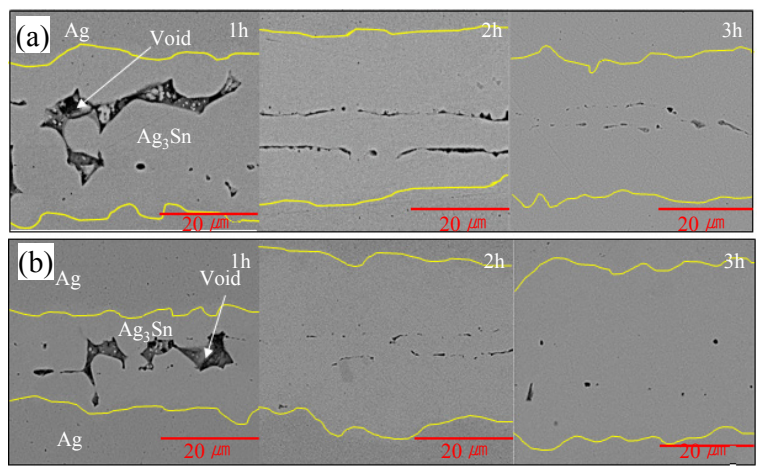

Fig. 4 Cross section images of $\mathrm{Ag} / \mathrm{Sn} / \mathrm{Ag}$ TLPB at various temperatures: (a) $250{ }^{\circ} \mathrm{C}$ and (b) $280{ }^{\circ} \mathrm{C}$

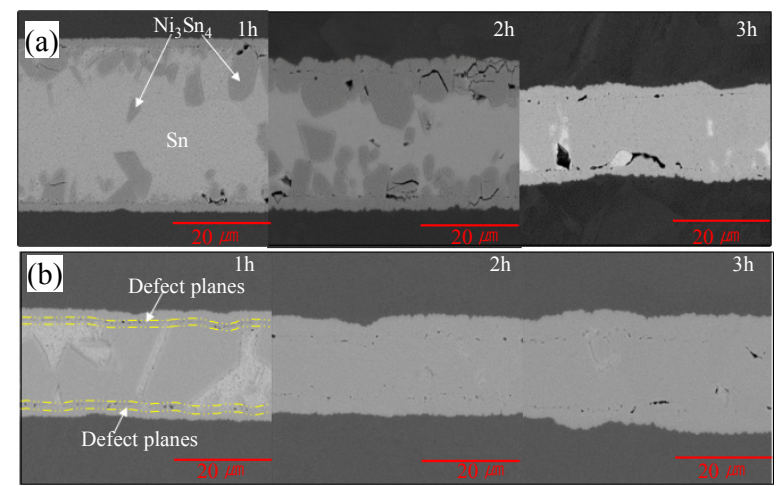

Fig. 5 Cross section images of $\mathrm{Ni} / \mathrm{Sn} / \mathrm{Ni} \mathrm{TLPB}$ at various temperautres: (a) $250{ }^{\circ} \mathrm{C}$ and (b) $280{ }^{\circ} \mathrm{C}$

간 화합물은 Fig. 5 에서와 같이 계면에서 성장하는 needle-like 형상의 IMC와 이로부터 떨어져 나온 $\mathrm{Ni}_{3} \mathrm{Sn}_{4}$ island의 형태로 관찰됐다. $\mathrm{Ni} / \mathrm{Sn} / \mathrm{Ni}$ TLPB에서는 특징적으로 metalization에서 약 $1 \mu \mathrm{m}$ 떨어진 $\mathrm{Ni}_{3} \mathrm{Sn}_{4}$ 층에서 void가 발견되었고, voids는 계면에서 자라는 $\mathrm{Ni}_{3} \mathrm{Sn}_{4}$ 와 접합부의 중앙에서 자라는 detached $\mathrm{Ni}_{3} \mathrm{Sn}_{4}$ island가 만나는 지점에서평행하게 나열되는 defect planes가 나타났다 ${ }^{7)}$. 그리고 다른 metalization과는 다 르게 $\mathrm{Ni} / \mathrm{Sn} / \mathrm{Ni} \mathrm{TLPB}$ 접합부의 중앙에는 void가 관 찰되지 않았으며 $350{ }^{\circ} \mathrm{C}$ 이상의 접합 온도에서 관찰됨 이 알려져 있다 ${ }^{7)} . \mathrm{Ni} / \mathrm{Sn} / \mathrm{Ni}$ TLPB에서는 Fig. $5 \mathrm{a}$ 와 $5 \mathrm{~b}$ 의 1 시간 접합 사진에서 알 수 있듯이 반응하지 않 은 $\mathrm{Sn}$ 이 interlayer에 존재하는 것을 알 수 있다. 이 는 $\mathrm{Ni}$ 의 융점이 높고 또한 확산 계수가 낮으므로 다른 metalization에 비해 같은 공정 조건에서도 접합부가 전체적으로 금속간 화합물을 형성하지 못했기 때문이 다. $250{ }^{\circ} \mathrm{C}$ 접합 온도에서는 3 시간 접합 시간에도 반 응하지 않은 $\mathrm{Sn}$ 이 존재하므로, $\mathrm{Ni} / \mathrm{Sn} / \mathrm{Ni}$ 의 최적 접합 온도는 균일한 금속간 화합물 형성과 기공률이 감소하 는 $280{ }^{\circ} \mathrm{C}$ 이다.

$\mathrm{Ag}, \mathrm{Cu}, \mathrm{Ni}$ 를 metalization으로 이용한 $\mathrm{Sn}$ sandwich structure TLPB에서 최적 온도조건이 $280{ }^{\circ} \mathrm{C}$ 임을 알아냈다. 동종 metalization의 최적 온도조건을 이용해 $\mathrm{Cu} / \mathrm{Sn} / \mathrm{Ag}$ 와 $\mathrm{Ni} / \mathrm{Sn} / \mathrm{Ag}$ 이종 metalization TLPB 접합을 수행하였다.

\section{2 이종 metalization TLPB}

Fig. 6 은 $\mathrm{Cu} / \mathrm{Sn} / \mathrm{Ag}$ 와 $\mathrm{Ni} / \mathrm{Sn} / \mathrm{Ag}$ 의 $280{ }^{\circ} \mathrm{C}$ 에서 $\mathrm{TLPB}$ 접합부 미세조직을 나타낸다. 동종 접합에서 최 적 조건을 선정한 결과로서 Figs. $6 \mathrm{a}$ 와 $6 \mathrm{~b}$ 에서 잔류하 는 $\mathrm{Sn}$ 은 발견되지 않았다. Fig. $6 \mathrm{a}$ 의 $\mathrm{Cu}$ metalization 계면에서는 $\mathrm{Cu}-\mathrm{Sn}$ 금속간 화합물이 형성되었 고, $\mathrm{Ag}$ metalization 계면에서는 $\mathrm{Ag}-\mathrm{Sn}$ 금속간 화합 


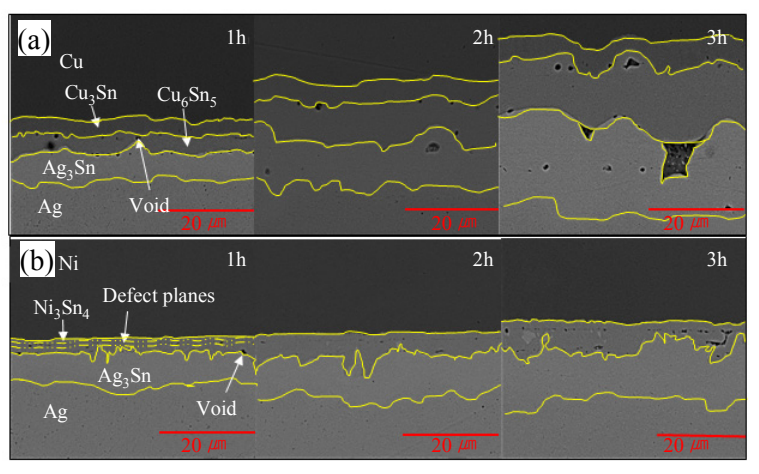

Fig. 6 TLPB images produced at $280{ }^{\circ} \mathrm{C}$ for dissimilar metalizations: (a) $\mathrm{Cu} / \mathrm{Sn} / \mathrm{Ag}$ and (b) $\mathrm{Ni} / \mathrm{Sn} / \mathrm{Ag}$

물이 형성되었다. 두 종류의 금속간 화합물이 핵생성 후 성장하면서 계면에서 만나게 되고 모두 scallop 형 상의 금속간 화합물이므로 Fig. $6 \mathrm{a}$ 의 3시간 접합 사진 처럼 $\mathrm{Cu}_{6} \mathrm{Sn}_{5}$ 와 $\mathrm{Ag}_{3} \mathrm{Sn}$ 의 계면에서 void가 형성될 수 있다. $\mathrm{Cu}-\mathrm{Sn}$ 금속간 화합물과 $\mathrm{Ag}-\mathrm{Sn}$ 금속간 화합물 의 두께는 $\mathrm{Cu}-\mathrm{Sn}$ 금속간 화합물이 평균적으로 $0.5 \mu \mathrm{m}$ 두꺼웠지만 큰 차이는 없었다. 이것은 $\mathrm{Cu}$ 의 $\mathrm{Sn}$ 내에서 $\mathrm{Cu}$ 의 $\mathrm{D}_{0}\left(\mathrm{D}_{0}(\mathrm{Cu}\right.$ in $\left.\mathrm{Sn})=1.8 \times 10^{-8} \mathrm{~m}^{2} \mathrm{~s}^{-1}\right)$ 와 $\mathrm{Ag}$ 의 $\mathrm{D}_{0}\left(\mathrm{D}_{0}(\mathrm{Ag}\right.$ in $\left.\mathrm{Sn})=2.60 \times 10^{-8} \mathrm{~m}^{2} \mathrm{~s}^{-1}\right)$ 가 유사하며 또한 확산에 대한 활성화 에너지 $\left(\mathrm{Q}_{(\mathrm{Cu}}\right.$ in $\left.\mathrm{Sn}\right)=\mathrm{Q}_{(\mathrm{Ag}}$ in $\left.\mathrm{Sn}\right)=$ $4200 \mathrm{cal} / \mathrm{mole}$ )도 같기 때문이다 ${ }^{8)}$. Fig. $6 \mathrm{~b}$ 에서는 $\mathrm{Ni}$ metalization 계면에서 $\mathrm{Ni}$ 가 $\mathrm{Sn}$ 내로 dissolution 되면서 $\mathrm{Ni}_{3} \mathrm{Sn}_{4}$ 가 형성되고 $\mathrm{Ag}$ metalization 계면에서 는 $\mathrm{Ag}_{3} \mathrm{Sn}$ 이 형성된다. $\mathrm{Ni} / \mathrm{Sn} / \mathrm{Ag}$ 에서는 $\mathrm{Ni}_{3} \mathrm{Sn}_{4}$ 의 두 께가 $\mathrm{Ag}_{3} \mathrm{Sn}$ 의 두께보다 작았다. 이는 $\mathrm{Ag}$ 의 확산계수 $\left(\mathrm{D}_{0}(\mathrm{Ag}\right.$ in $\left.\mathrm{Sn})=2.60 \times 10^{-8} \mathrm{~m}^{2} \mathrm{~s}^{-1}\right)$ 와 $\mathrm{Ni}$ 의 확산계수 $\left(\mathrm{D}_{0(\mathrm{Ni}}\right.$ in $\left.\left.\mathrm{Sn}\right)=2.30 \times 10^{-8} \mathrm{~m}^{2} \mathrm{~s}^{-1}\right)$ 가 유사하지만 확산에 대한 활성화 에너지는 $\mathrm{Ni}\left(\mathrm{Q}_{(\mathrm{Ni}}\right.$ in $\left.\left.\mathrm{Sn}\right)=4530 \mathrm{cal} / \mathrm{mole}\right)$ 가 $\mathrm{Ag}$ 보다 크기 때문이다 ${ }^{8)}$. 이에 대한 내용을 Table 1 에 정리하였다. $\mathrm{Ni} / \mathrm{Sn} / \mathrm{Ni}$ 접합과 마찬가지로 $\mathrm{Ni}$ metalization 부근에서 평행하게 정렬된 defect planes이 나타났다.

\subsection{Lap-shear test}

$\mathrm{Cu} / \mathrm{Sn} / \mathrm{Ag}$ 와 $\mathrm{Ni} / \mathrm{Sn} / \mathrm{Ag}$ 를 $280{ }^{\circ} \mathrm{C}$ 에서 1, 2, 3시

Table 1 Values of $\mathrm{D}_{0}$ and $\mathrm{Q}$ for the diffusion of silver, copper, and nickel in $\operatorname{tin}^{8)}$

\begin{tabular}{|c|c|c|}
\hline Element & $\mathrm{D}_{0}\left(\mathrm{~m}^{2} / \mathrm{sec}\right)$ & $\mathrm{Q}(\mathrm{cal} / \mathrm{mole})$ \\
\hline $\mathrm{Ag}$ & $2.6 \times 10^{-8}$ & 4200 \\
\hline $\mathrm{Cu}$ & $1.8 \times 10^{-8}$ & 4200 \\
\hline $\mathrm{Ni}$ & $2.3 \times 10^{-8}$ & 4530 \\
\hline
\end{tabular}

Table 2 Shear strength values for each condition

\begin{tabular}{|c|c|c|c|c|c|c|}
\hline \multirow{2}{*}{ Metalization } & \multicolumn{2}{|c|}{$1 \mathrm{~h}$} & \multicolumn{2}{c|}{$2 \mathrm{~h}$} & \multicolumn{2}{c|}{$3 \mathrm{~h}$} \\
\cline { 2 - 7 } & $\begin{array}{c}\text { Strength } \\
(\mathrm{MPa})\end{array}$ & $\begin{array}{c}\text { Std. } \\
(\mathrm{MPa})\end{array}$ & $\begin{array}{c}\text { Strength } \\
(\mathrm{MPa})\end{array}$ & $\begin{array}{c}\text { Std. } \\
(\mathrm{MPa})\end{array}$ & $\begin{array}{c}\text { Strength } \\
(\mathrm{MPa})\end{array}$ & $\begin{array}{c}\text { Std. } \\
(\mathrm{MPa})\end{array}$ \\
\hline $\mathrm{Cu} / \mathrm{Sn} / \mathrm{Ag}$ & 31 & 2.1 & 28 & 1.4 & 30 & 1.4 \\
\hline $\mathrm{Ni} / \mathrm{Sn} / \mathrm{Ag}$ & 28 & 3.5 & 32 & 4.9 & 32 & 4.2 \\
\hline
\end{tabular}

간 접합한 시편을 lap-shear test를 수행하였고, Table 2에 측정한 lap-shear test 결과를 나타내었다. Fig. 6 과 같이 접합부의 두께는 각 조건마다 상이하지만 ultimate shear strength에는 무관함이 알려져 있다 ${ }^{9)}$. 전단 강도는 평균 $30 \mathrm{MPa}$ 로 기존의 솔더를 이용한 접 합부보다 높은 강도값을 나타냈다 ${ }^{10)}$. 보통 TLPB 이후 작동 환경에서의 aging 시험을 시행하게 되면 aging 시 간이 증가함에 따라 전단강도가 약간 상승하게 된다 ${ }^{11)}$. 이는 TLPB의 접합부가 고온 환경에서 균질화 단계에 이르게 되기 때문이다. 충분한 균질화 과정을 거치게 되 면 접합부는 궁극적으로 metalization으로 이루어진 고 용체가 된다 ${ }^{12)}$. 하지만 본 연구에서의 시간은 단순 접 합 공정에 소요된 시간으로서 aging에 의한 고용강화 효과를 기대하기는 어렵다. 따라서 접합 시간에 따라 전 단강도가 소폭 증가하거나 오히려 소폭 감소하였다. 전 단강도의 감소는 접합 시 생성되는 기공의 영향이 지배 적이므로 최대의 전단강도를 갖는 접합 시간이 최적의 공정 조건이라 할 수 있다. 따라서 Table 2에 의하면 $280{ }^{\circ} \mathrm{C}$ 에서 $\mathrm{TLPB}$ 최소 요구 접합 시간은 $\mathrm{Cu} / \mathrm{Sn} /$ $\mathrm{Ag}$ 은 1 시간이고 $\mathrm{Ni} / \mathrm{Sn} / \mathrm{Ag}$ 은 2 시간이라고 판단할 수 있다.

Fig. 7 은 lap-shear test 후 파단면을 나타낸다. Fig. $7 \mathrm{a}$ 와 같이 $\mathrm{Cu} / \mathrm{Sn} / \mathrm{Ag}$ TLPB 접합부의 파단은 $\mathrm{Ag}_{3} \mathrm{Sn}$ 금속간 화합물 층 내에서 발생하였다. Fig. 7a의 Area 1 은 $\mathrm{Ag}_{3} \mathrm{Sn}$ 과 $\mathrm{Cu}_{6} \mathrm{Sn}_{5}$ 사이에 기공이 존재했음을 의미 하며 Area 2은 $\mathrm{Ag}_{3} \mathrm{Sn}$ 층내에서 파단이 발생하였으며 응력 방향으로의 shear band를 나타낸다. Fig. $7 \mathrm{~b}$ 는 $\mathrm{Ni} / \mathrm{Sn} / \mathrm{Ag} \mathrm{TLPB}$ 접합부 파단면을 나타낸다. 파단은 $\mathrm{Ni}_{3} \mathrm{Sn}_{4}$ 와 $\mathrm{Ag}_{3} \mathrm{Sn}$ 의 경계면에서 발생하였다. Fig. $7 \mathrm{~b}$ 의 Area 3 은 $\mathrm{Ni}_{3} \mathrm{Sn}_{4}$ 를 나타내고 취성이 강하므로 ${ }^{13)}$ shear band를 관찰 할 수 없었지만 Area 4는 상대적으로 연 한 $\mathrm{Ag}_{3} \mathrm{Sn}$ 이며 shear band를 관찰할 수 있었다. 따라서 $\mathrm{Cu} / \mathrm{Sn} / \mathrm{Ag}$ 의 경우 $\mathrm{Cu}_{6} \mathrm{Sn}_{5}$ 보다 상대적으로 연한 $\mathrm{Ag}_{3} \mathrm{Sn}$ 층에서 파단이 발생하였고 ${ }^{14)}$ 이로 인해 취성이 강한 $\mathrm{Ni}_{3} \mathrm{Sn}_{4}$ 와 연질인 $\mathrm{Ag}_{3} \mathrm{Sn}$ 이 공존하는 파단면을 가진 $\mathrm{Ni} / \mathrm{Sn} / \mathrm{Ag}$ 접합부보다 전단 강도가 낮게 측정되었다. 


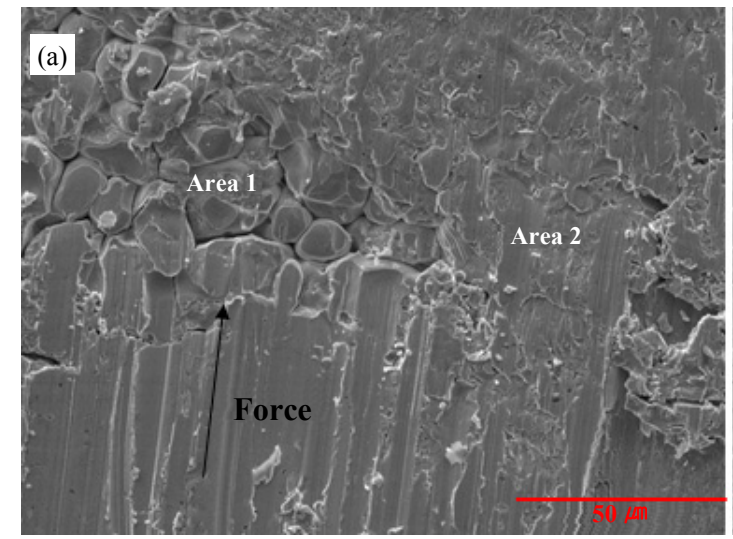

Area 1
\begin{tabular}{|c|c|c|}
\hline Element & $\mathrm{Wt} \%$ & $\mathrm{At} \%$ \\
\hline $\mathrm{AgL}$ & 70.98 & 72.91 \\
\hline $\mathrm{SnL}$ & 29.02 & 27.09 \\
\hline Matrix & Correction & ZAF \\
\hline
\end{tabular}

Area 2

\begin{tabular}{|c|c|c|}
\hline Element & $\mathrm{Wt} \%$ & $\mathrm{At} \%$ \\
\hline $\mathrm{AgL}$ & 70.67 & 72.61 \\
\hline $\mathrm{SnL}$ & 29.33 & 27.39 \\
\hline Matrix & Correction & $\mathrm{ZAF}$ \\
\hline
\end{tabular}

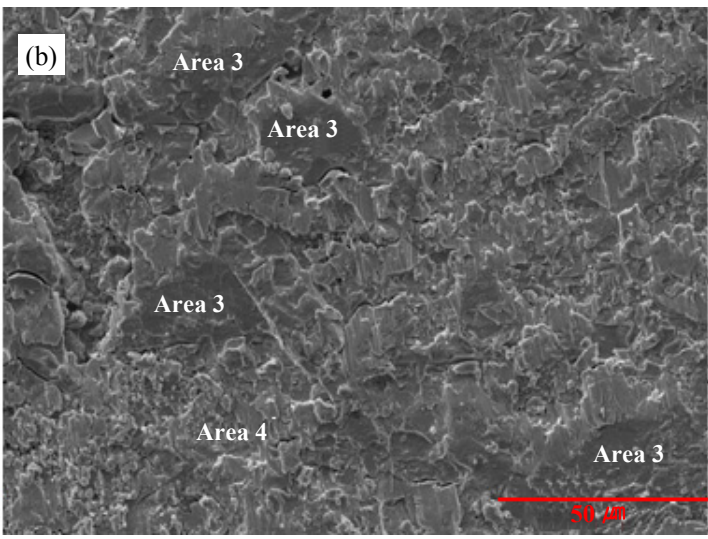

Area 3

\begin{tabular}{|c|c|c|}
\hline Element & $\mathrm{Wt} \%$ & $\mathrm{At} \%$ \\
\hline $\mathrm{AgL}$ & 02.78 & 02.43 \\
\hline $\mathrm{SnL}$ & 72.47 & 57.71 \\
\hline Nik & 24.76 & 39.86 \\
\hline Matrix & Correction & $\mathrm{ZAF}$ \\
\hline
\end{tabular}

Area 4

\begin{tabular}{|c|c|c|}
\hline Element & $\mathrm{Wt} \%$ & $\mathrm{At} \%$ \\
\hline $\mathrm{AgL}$ & 64.49 & 64.76 \\
\hline $\mathrm{SnL}$ & 32.47 & 29.64 \\
\hline Nik & 03.04 & 05.61 \\
\hline Matrix & Correction & $\mathrm{ZAF}$ \\
\hline
\end{tabular}

Fig. 7 Fracture surfaces after lap-shear test for dissimilar TLPBs: (a) $\mathrm{Cu} / \mathrm{Sn} / \mathrm{Ag}$ and (b) Ni/Sn/Ag

\section{4. 결 론}

본 연구는 $\mathrm{Sn}$ 을 interlayer로 하는 $\mathrm{Cu}, \mathrm{Ag}, \mathrm{Ni}$ metalization TLPB 동종 접합 공정 변수에 대한 특 성 평가를 시행하였다. 동종 접합 실험에서 결정된 최 적 공정 변수를 이용하여 $\mathrm{Cu} / \mathrm{Sn} / \mathrm{Ag}, \mathrm{Ni} / \mathrm{Sn} / \mathrm{Ag}$ 이종 metalization TLPB를 분석 하였고, 다음과 같은 결 론을 도출하였다.

1) 접합 온도 $250{ }^{\circ} \mathrm{C}$ 에서 $\mathrm{TLPB}$ 를 수행한 경우 $\mathrm{Cu} /$ $\mathrm{Sn} / \mathrm{Cu}$ 접합부는 접합 시간이 증가할수록 $\mathrm{Cu}_{6} \mathrm{Sn}_{5}$ 보다 $\mathrm{Cu}_{3} \mathrm{Sn}$ 의 분율이 증가하였다. 그리고 $250{ }^{\circ} \mathrm{C} 3$ 시간 접 합부에서는 $\mathrm{Cu}_{3} \mathrm{Sn}$ 과 $\mathrm{Cu}_{6} \mathrm{Sn}_{5}$ 가 공존하는 접합부가 형 성됐으나 $280{ }^{\circ} \mathrm{C}, 3$ 시간에서는 $\mathrm{Cu}_{3} \mathrm{Sn}$ 단상으로 존재 하였다. 이는 온도가 증가함에 따라 $\mathrm{Cu}$ 의 확산계수가 증 가하기 때문이다. 또한 $250{ }^{\circ} \mathrm{C}$ 에서는 접합부의 $\mathrm{Cu}_{6} \mathrm{Sn}_{5}$ 층에서 큰 기공들이 존재하였으나 $280{ }^{\circ} \mathrm{C}$ 에서는 기공 분율이 현저히 감소하였다. 따라서 접합온도 $280{ }^{\circ} \mathrm{C}$ 가 최적 공정 온도이다.

2) $\mathrm{Ag} / \mathrm{Sn} / \mathrm{Ag}$ 접합부는 $\mathrm{Ag}_{3} \mathrm{Sn}$ 단상으로 구성되었 다. 기공 분율은 접합 시간에 따라 $250{ }^{\circ} \mathrm{C}$ 에서 $8 \%$, $2 \%, 0.7 \%$ 이고, $280{ }^{\circ} \mathrm{C}$ 에서는 $7 \%, 0.3 \%, 0.3 \%$ 로 현 저하게 감소하였다. 이러한 기공 분율의 감소는 확산계 수의 온도의존성에 의한 것으로 판단된다. 따라서 $280{ }^{\circ} \mathrm{C}$ 에서의 가장 건전한 접합부를 형성하였으며 최적 공정 온도로 결정하였다.

3) $\mathrm{Ni} / \mathrm{Sn} / \mathrm{Ni}$ 의 접합부는 $\mathrm{Ni}_{3} \mathrm{Sn}_{4}$ 혹은 $\mathrm{Ni}_{3} \mathrm{Sn}_{4}$ 와 $\mathrm{Sn}$ 으로 구성되었다. $250{ }^{\circ} \mathrm{C}$ 에서 $1,2,3$ 시간 모두 잔류 $\mathrm{Sn}$ 이 존재하였다. 이는 $\mathrm{Ni}$ 의 확산계수가 $\mathrm{Cu}, \mathrm{Ag}$ 보다 낮기 때문이다. 하지만 $280{ }^{\circ} \mathrm{C} 2$, 3시간에서 접합부는
$\mathrm{Ni}_{3} \mathrm{Sn}_{4}$ 단상으로 이루어졌다. 따라서 $\mathrm{Ni} / \mathrm{Sn} / \mathrm{Ni}$ 의 건 전한 접합부는 $280{ }^{\circ} \mathrm{C}$ 에서 형성됨 을 확인하였다.

4) 동종 접합에서 결정된 접합 온도 $280{ }^{\circ} \mathrm{C}$ 를 $\mathrm{Cu} /$ $\mathrm{Sn} / \mathrm{Ag}$ 와 $\mathrm{Ni} / \mathrm{Sn} / \mathrm{Ag}$ 에 1, 2, 3시간동안 접합하였다. 모든 접합시간에서 접합부는 금속간 화합물로 구성되었 다. $\mathrm{Cu} / \mathrm{Sn} / \mathrm{Ag}$ 는 $\mathrm{Cu}_{3} \mathrm{Sn}, \mathrm{Cu}_{6} \mathrm{Sn}_{5}, \mathrm{Ag}_{3} \mathrm{Sn}$ 으로 존재 하였고 $\mathrm{Ni} / \mathrm{Sn} / \mathrm{Ag}$ 는 $\mathrm{Ni}_{3} \mathrm{Sn}_{4}, \mathrm{Ag}_{3} \mathrm{Sn}$ 으로 존재하였다. $\mathrm{Cu} / \mathrm{Sn} / \mathrm{Ag}$ 에서 $\mathrm{Cu}-\mathrm{Sn}$ 금속간 화합물과 $\mathrm{Ag}-\mathrm{Sn}$ 금속 간 화합물의 두께가 비슷하였다. 이는 $\mathrm{Cu}$ 와 $\mathrm{Ag}$ 의 확산 계수가 유사하기 때문이다. 하지만 $\mathrm{Ni} / \mathrm{Sn} / \mathrm{Ag}$ 에서 $\mathrm{Ag}-$ $\mathrm{Sn}$ 금속간 화합물이 $\mathrm{Ni}-\mathrm{Sn}$ 금속간 화합물 두께보다 더 두꺼웠다. 이는 $\mathrm{Ag}$ 의 $\mathrm{D}_{0}\left(\mathrm{D}_{0}(\mathrm{Ag}\right.$ in $\mathrm{Sn})=2.60 \times$ $\left.10^{-8} \mathrm{~m}^{2} \mathrm{~s}^{-1}\right)$ 와 $\mathrm{Ni}$ 의 $\mathrm{D}_{0}\left(\mathrm{D}_{0}(\mathrm{Ni}\right.$ in $\mathrm{Sn})=2.30 \times 10^{-8}$ $\mathrm{m}^{2} \mathrm{~s}^{-1}$ )가 유사하지만 확산에 대한 활성화 에너지는 $\mathrm{Ni}$ $\left(\mathrm{Q}_{(\mathrm{Ni}}\right.$ in $\left.\left.\mathrm{Sn}\right)=4530 \mathrm{cal} / \mathrm{mole}\right)$ 가 $\mathrm{Ag}\left(\mathrm{Q}_{(\mathrm{Ag}}\right.$ in $\left.\mathrm{sn}\right)=$ $4200 \mathrm{cal} / \mathrm{mole}$ )보다 크기 때문이다. Lap-shear test 결과 $\mathrm{Cu} / \mathrm{Sn} / \mathrm{Ag}$ 는 최소 1 시간 $\mathrm{Ni} / \mathrm{Sn} / \mathrm{Ag}$ 의 경우 최소 2 시간의 접합 시간이 요구됨을 전단 강도 값을 통해 판 단하였다. $\mathrm{Ni} / \mathrm{Sn} / \mathrm{Ag}$ 의 접합부 파단면은 shear band 가 관찰되는 $\mathrm{Ag}_{3} \mathrm{Sn}$ 과 취성이 강한 $\mathrm{Ni}_{3} \mathrm{Sn}_{4}$ 로 확인되었 다. $\mathrm{Cu} / \mathrm{Sn} / \mathrm{Ag}$ 의 접합부 파단면은 $\mathrm{Ag}_{3} \mathrm{Sn}$ 으로만 구성 되었으며 shear band가 관찰되었다. 따라서 취성이 강한 $\mathrm{Ni}_{3} \mathrm{Sn}_{4}$ 와 상대적으로 연한 $\mathrm{Ag}_{3} \mathrm{Sn}$ 이 공존하는 층 에서 파단이 발생하는 $\mathrm{Ni} / \mathrm{Sn} / \mathrm{Ag}$ 접합부가 $\mathrm{Cu} / \mathrm{Sn} / \mathrm{Ag}$ 접합부보다 더 높은 강도값을 나타내는 경향을 보였다.

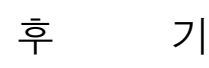

이 논문은 부산대학교 자유과제 학술연구비(2년)에 의 
하여 연구되었습니다.

ORCID: Sunghyun Sohn: http://orcid.org/0000-0001-8722-3407

ORCID: Kyung Mox Cho: http://orcid.org/0000-0001-5317-2365

ORCID: Namhyun Kang: http://orcid.org/0000-0002-9460-5128

\section{References}

1. A. Drevin-Bazin, F. Lacroix, and J. -F. Barbot, SiC Die Attach for High-Temperature Applications, J. Electron. Mate. 43(3) (2014) 695-701.

https://doi.org/10.1007/s11664-013-2718-5

2. H. Zhang, J. Minter, and N. -C. Lee, A Brief Review on High-Temperature, Pb-Free Die-Attach Materials, J. Electron. Mater. 48(1) (2019) 201-210.

https://doi.org/10.1007/s11664-018-6707-6

3. J. H. Bang, D. Y. Yu, Y. H. Ko, J. H. Kim and C. W. Lee, Joint Property of $\mathrm{Sn}-\mathrm{Cu}-\mathrm{Cr}(\mathrm{Ca})$ Middle Temperature Solder for Automotive Electronic Module, J. Weld. Join. 31(5) (2013) 54-58.

https://dx.doi.org/10.5781/KWJS.2013.31.5.54

4. P. G. Neudeck, R. S. Okojie and L. -Y. Chen, High-temperature electronics - a Role for wide bandgap semiconductors?, Proc. IEEE. 90(6) (2002) 1065-1076. https://doi.org/10.1109/JPROC.2002.1021571

5. T. Hu, H. Chen and M. Li, Die attach materials with high remelting temperatures created by bonding $\mathrm{Cu} @ \mathrm{Sn}$ microparticles at lower temperatures, Mater. Des. 108(10) (2016) 383-390. https://doi.org/10.1016/j.matdes.2016.06.099

6. H. Shao, A. Wu, Y. Bao and Y. Zhao, Elimination of pores in Ag-Sn TLP bonds by the introduction of dissimilar intermetallic phases, J. Mater. Sci. 52(6) (2016) 3508-3519. https://doi.org/10.1007/s10853-016-0645-6
7. A. Lis and C. Leinenbach, Effect of Process and Service Conditions on TLP-Bonded Components with (Ag,Ni-)Sn Interlayer Combinations, J. Electron. Mater. 44(11) (2015) 4576-4588. https://doi.org/10.1007/s11664-015-3982-3

8. C. H. Ma and R. A. Swalin, A study of solute diffusion in liquid tin, Acta Mater. 8(6) (1960) 388-395. https://doi.org/10.1016/0001-6160(60)90008-0

9. Y. L. Shen, N. Chawla, E. S. Ege and X. Deng, Deformation analysis of lap-shear testing of solder joints, Acta Mater. 53(9) (2005) 2633- 2642.

https://doi.org/10.1016/j.actamat.2005.02.024

10. W. S. Hong and C. M. Oh, Degradation Behavior of Solder Joint and Implementation Technology for Lead- free Automotive Electronics, J. Weld. Join. 31(3) (2013) 22-30. https://dx.doi.org/10.5781/KWJS.2013.31.3.22

11. Q. Guo, S. Sun, Z. Zhang, H. Chen and M. Li, Microstructure evolution and mechanical strength evaluation in $\mathrm{AgSnCu}$ TLP bonding interconnection during aging test, MICROELECTRON RELIAB. 80(2018) 144-148. https://doi.org/10.1016/j.microrel.2017.12.001

12. N. S. Bosco and F. W. Zok, Critical interlayer thickness for transient liquid phase bonding in the $\mathrm{Cu}-\mathrm{Sn}$ system, Acta Mater. 52(10) (2004) 2965-2972. https://doi.org/10.1016/j.actamat.2004.02.043

13 R. J. Fields and S. R. Low and G. K. Lucey, Physical and mechanical properties of intermetallic compounds commonly found in solder joints, Metal Science of Join. Proceedings of TMS Symposium, Cincinnati, USA (1991).

14. R. R. Chromik, R. P. Vinci, S. L. Allen and M. R. Notis, Measuring the mechanical properties of $\mathrm{Pb}$-free solder and $\mathrm{Sn}$-based intermetallics by nanoindentation, JOM. 55(6) (2003) 66-69. https://doi.org/10.1007/s11837-003-0144-5 